\title{
The Very Large G-Protein-Coupled Receptor VLGR1: A Component of the Ankle Link Complex Required for the Normal Development of Auditory Hair Bundles
}

\author{
JoAnn McGee, ${ }^{\star *}$ Richard J. Goodyear, ${ }^{2 *}$ D. Randy McMillan, ${ }^{3 *}$ Eric A. Stauffer, ${ }^{4}$ Jeffrey R. Holt, ${ }^{4}$ Kirsten G. Locke, ${ }^{5}$ \\ David G. Birch, ${ }^{5}$ P. Kevin Legan, ${ }^{2}$ Perrin C. White, ${ }^{3}$ Edward J. Walsh, ${ }^{1}$ and Guy P. Richardson ${ }^{2}$ \\ ${ }^{1}$ Developmental Auditory Physiology Laboratory, Boys Town National Research Hospital, Omaha, Nebraska 68131, ${ }^{2}$ School of Life Sciences, University of \\ Sussex, Falmer, Brighton BN1 9QG, United Kingdom, ${ }^{3}$ Department of Pediatrics, University of Texas Southwestern Medical Center, Dallas, Texas 75390- \\ 9063, ${ }^{4}$ Department of Neuroscience, University of Virginia School of Medicine, Charlottesville, Virginia 22908, and ${ }^{5}$ Retina Foundation of the Southwest, \\ Dallas, Texas 75225
}

Sensory hair bundles in the inner ear are composed of stereocilia that can be interconnected by a variety of different link types, including tip links, horizontal top connectors, shaft connectors, and ankle links. The ankle link antigen is an epitope specifically associated with ankle links and the calycal processes of photoreceptors in chicks. Mass spectrometry and immunoblotting were used to identify this antigen as the avian ortholog of the very large G-protein-coupled receptor VLGR1, the product of the Usher syndrome USH2C (Mass1) locus. Like ankle links, Vlgr1 is expressed transiently around the base of developing hair bundles in mice. Ankle links fail to form in the cochleae of mice carrying a targeted mutation in Vlgr1 (Vlgr1/del7TM), and the bundles become disorganized just after birth. FM1-43 [ $N$-(3-triethylammonium)propyl)-4-(4-(dibutylamino)styryl) pyridinium dibromide] dye loading and whole-cell recordings indicate mechanotransduction is impaired in cochlear, but not vestibular, hair cells of early postnatal Vlgr1/del7TM mutant mice. Auditory brainstem recordings and distortion product measurements indicate that these mice are severely deaf by the third week of life. Hair cells from the basal half of the cochlea are lost in 2-month-old Vlgr1/del7TM mice, and retinal function is mildly abnormal in aged mutants. Our results indicate that Vlgr 1 is required for formation of the ankle link complex and the normal development of cochlear hair bundles.

Key words: cochlea; hair cell; Usher syndrome; knock-out mice; GPCR; retina

\section{Introduction}

The hair bundle is a mechanosensitive structure located at the apical pole of the sensory hair cell. It is composed of numerous modified microvilli (stereocilia) that are arrayed in rows of increasing height across the apical surface of the hair cell. Stereocilia are coupled to one another by a number of different link types. Four morphologically and biochemically distinct link types can be distinguished extending between the stereocilia of mature hair bundles in the avian hearing organ: tip links, horizontal top connectors, shaft connectors, and ankle links (Goodyear and Richardson, 1992, 1999). In the mature mouse cochlea, tip links and horizontal top connectors are the only inter-stereocilial links as-

Received Feb. 16, 2006; revised May 1, 2006; accepted May 2, 2006.

This research was supported by National Institutes of Health Grants EY016247 (P.C.W.), DC004566 (E.J.W.), DC004662 (Boys Town National Research Hospital), EY05235 (D.G.B.), and DC005439 (J.R.H.) and Wellcome Trust Grant 071394/Z/03/Z (G.P.R.). We thank Dr. Kathryn Lilley (Cambridge Centre for Proteomics, UK) for assistance with mass spectrometry, Drs. Dominic Cosgrove and Michael Weston (both from Boys Town National Research Hospital, Omaha, NE) for providing the antibody directed against mouse Vlgr1 used in this study, as well as Kelli Black, Jo Ellen Boche, Emily Harris, Megan Korte, and Laura Stone for technical assistance.

*.M., R.J.G., and D.R.M. contributed equally to this work

Correspondence should be addressed to Dr. Perrin C. White, Department of Pediatrics, University of Texas Southwestern Medical Center, 5323 Harry Hines Boulevard, Dallas, TX 75390-9063. E-mail: perrin.white@utsouthwestern.edu.

D0I:10.1523/JNEUROSCI.0693-06.2006

Copyright $\odot 2006$ Society for Neuroscience $\quad 0270-6474 / 06 / 266543-11 \$ 15.00 / 0$ sociated with the hair bundle (Goodyear et al., 2005). Ankle links and an additional link type, the transient lateral link, are, however, both prominent features of developing auditory hair bundles in the mouse inner ear (Goodyear et al., 2005; Michel et al., 2005).

Tip links are thought to gate the mechanotransducer channel of the hair cell (Pickles et al., 1984; Assad et al., 1991), whereas other link types may serve to maintain the structural integrity of the hair bundle and/or orchestrate its development. Some of the molecules that form these various link types have been or are in the process of being identified. Cadherin $23(\mathrm{Cdh})$ is a component of the transient lateral links found on developing hair bundles (Michel et al., 2005) and may also be associated with the tip links of mature hair bundles (Siemens et al., 2004; Sollner et al., 2004), and the receptor-like inositol lipid phosphatase Ptprq (protein tyrosine phosphatase, receptor type Q) is a constituent of the shaft connectors (Goodyear and Richardson, 1992, 2003; Goodyear et al., 2003).

The ankle link antigen (ALA) is a calcium-dependent epitope associated with the ankle links of sensory hair bundles in the inner ear (see Fig. 1A) and the ciliary calyx of photoreceptors in the eye (see Fig. 1B) (Goodyear and Richardson, 1999). It was identified as a large, Concanavalin A (ConA) reactive glycoprotein using a monoclonal antibody (mAb) generated from a 
mouse immunized with a crude membrane fraction derived from the sensory organs of the chick inner ear (Goodyear and Richardson, 2003). In this study, we identify the ALA as the avian ortholog of the very large G-protein-coupled receptor VLGR1, the largest known cell-surface protein (McMillan et al., 2002) and a product of the Usher syndrome 2C locus (Weston et al., 2004). Usher syndrome consists of sensorineural deafness, retinitis pigmentosa, and, in some forms, vestibular dysfunction. It has a frequency of 1 in 25,000 in the United States and includes three subtypes numbered in descending order of severity, with type 2 being the most frequent.

By deleting the transmembrane and cytoplasmic domains of Vlgr1 in mice, we show that Vlgr1 is an essential component of the ankle link complex and is required for the normal maturation of mouse auditory hair bundles. Vlgr 1 mutant mice exhibit an auditory phenotype similar to that observed in patients with Usher syndrome type 2 .

\section{Materials and Methods}

Immunoprecipitation from chick retina. Retinas were dissected from the eyes of 1-2 d posthatch chicks in cold PBS containing a mixture of protease inhibitors ( $1 \mathrm{~mm}$ PMSF, $2 \mathrm{~mm}$ benzamidine, $1 \mu \mathrm{g} / \mathrm{ml}$ leupeptin, and $1 \mu \mathrm{g} / \mathrm{ml}$ pepstatin) and stored frozen at $-80^{\circ} \mathrm{C}$ until use. Frozen retinas were thawed in ice-cold extraction buffer (1\% Triton X-100 in $150 \mathrm{~mm}$ $\mathrm{NaCl}, 5 \mathrm{~mm} \mathrm{CaCl}_{2}$, and $20 \mathrm{~mm}$ HEPES, pH 7.2) containing $2 \times$ concentrated EDTA-free protease inhibitor mixture (Roche, Lewes, UK), homogenized, and centrifuged at $41,000 \times g$ for $30 \mathrm{~min}$ at $4^{\circ} \mathrm{C}$. The resultant supernatant was filtered through \#1 grade Whatman (Maidstone, UK) filter paper and centrifuged for an additional $30 \mathrm{~min}$ at 48,000 $\times \mathrm{g}$. Aliquots of the supernatant were incubated overnight at $4^{\circ} \mathrm{C}$ with protein A Sepharose beads that had been preloaded with anti-ALA IgG $\operatorname{Iga}_{2 \mathrm{a}} \mathrm{mAb}$ $\mathrm{H} 28$ or an irrelevant control mAb of the same isotype (anti-hair-cell antigen $\mathrm{mAb} \mathrm{H} 27)$. Beads were collected and washed six times with cold PBS containing $0.1 \%$ Triton X-100 by brief low-speed centrifugation or sedimentation at $1 \times g$, and bound proteins were eluted by heating the beads for $4 \mathrm{~min}$ at $100^{\circ} \mathrm{C}$ in an equal volume of $2 \times$ concentrated SDSPAGE sample buffer. Eluted proteins were resolved on 6\% SDS polyacrylamide gels and either visualized by staining with Coomassie Brilliant Blue or transferred to HybondP using semidry electroblotting.

Mass spectrometry. Slices of acrylamide gel containing the Coomassiestained ALA band immunoprecipitated from a total of 400 retinas were reduced, carboxyamidomethylated, and digested to peptides with trypsin on a MassPrepStation (Waters Associates, Milford, MA). The resultant peptides were desalted, concentrated, and applied to a capillary liquid chromatography system coupled to a quadropole time-of-flight mass spectrometer (LC-MS/MS) (Qtof2; Waters Associates). Separation of the peptides was accomplished using a PepMap C18 reverse-phase column (70 mm inner diameter, $15 \mathrm{~mm}$ column; LC Packings, Sunnyvale, CA) on a Waters Associates capillary liquid chromatography system attached to the spectrometer. The MS/MS data obtained from the ALA band was used to search the National Center for Biotechnology Information human and mouse databases using the MASCOT search engine (http:// www.matrixscience.com/search_form_select.html). Probability based MASCOT scores were used to evaluate identification, with matches with a $p<0.05$ for random occurrence being considered significant.

Immunoblot analysis. The predicted nucleotide sequence for chicken Vlgrl (ENSGALT00000023622) was obtained by searching the University of California, Santa Cruz genome browser (http://genome.ucsc.edu/ cgi-bin/hgGateway) with the mouse Vlgrl sequence (GenBank accession number AF435926) using BLAT. Primers GgVlgr1F1 (ggcagccatatgCACAATCAACTTTGTTGCCCCGTGA) and GgVlgr1 (gcagccggatcctTAGAGATGGGTGTCTGCTAT) were used to amplify bases 17,983-18,438 of ENSGALT00000023622, encoding the C-terminal 151 amino acids of the predicted chicken Vlgr1. Primers GgVlgr1F2 (ggcagccatatgCCTGCTAACGTCACAGCAATTGTGTCG) and GgVlgr2 (gcagccggatcctTATCTGAATGAATCGCACAGGGCTGTCA) were used to amplify bases 163-784 of ENSGALT00000023622, encoding 207 amino acids close to the $\mathrm{N}$ terminus of the protein. PCR products were amplified from chick retina first-strand cDNA using a mixture of Pfu (Stratagene, Amsterdam, The Netherlands) and Taq (Bioline, London, UK) polymerases, cleaved with NdeI and BamHI, ligated into pET15b, and transformed into Escherichia coli XL1-blue. Recombinants were identified by PCR screening, and the inserts were sequenced. Recombinants containing the desired inserts were transformed into E. coli BL21 (DE3)PlysS, and expression of the His-tagged fusion proteins was induced with isopropyl- $\beta$-D-thiogalactopyranoside. Fusion proteins were purified using $\mathrm{Ni}^{2+}$ affinity chromatography and used to immunize mice. Serum M112 was obtained from a mouse immunized with the recombinant C-terminal domain of chick Vlgr1, and serum M113 was obtained from a mouse immunized with the protein fragment located close to the $\mathrm{N}$ terminus.

Protein blots on HybondP were preblocked in TBS/0.05\% Tween 20 containing either 3\% low-fat milk powder (for antibodies) or 3\% BSA (for ConA) and incubated overnight in preblocking solution containing mouse anti-chick VLGR1 sera (a mixture of M112 and M113 sera, both at 1:1000 dilution) or biotinylated ConA ( $5 \mu \mathrm{g} / \mathrm{ml}$; Vector Laboratories, Peterborough, UK). Blots were then washed, reacted for $2 \mathrm{~h}$ with either alkaline phosphatase-conjugated goat anti-mouse Ig (1:1000 dilution; DakoCytomation, High Wycombe, UK) for antibody detection or alkaline phosphatase-conjugated streptavidin (1:1000 dilution; Vector Laboratories) for ConA detection in TBS $/ 0.05 \%$ Tween 20 with 3\% low-fat milk powder, washed extensively, and reacted with nitrobluetetrazolium-chloride/5-bromo-4-chloro-indolyl-phosphate (Roche).

Mice. Mice carrying a targeted mutation in Vlgr1 (Vlgr1/del7TM) were described previously (McMillan and White, 2004). The mice used in these studies were intercrossed $\mathrm{F} 3$ generation mice and their offspring on a hybrid C57BL/6J × 129X1/Sv background.

All procedures involving the use of animals were approved by the appropriate Animal Care and Use Committee of each participating institution.

Fluorescence microscopy. Before fixation, inner ear tissues were dissected in PBS, and cochlear cultures (see below) were washed in HEPESbuffered (10 mM), pH 7.2, HBSS (HBHBSS). Samples were then fixed for $1 \mathrm{~h}$ in $4 \%$ paraformaldehyde in $0.1 \mathrm{M}$ sodium phosphate buffer, $\mathrm{pH} 7.2$, washed three times in PBS, and preblocked in TBS containing $10 \%$ horse serum and $0.1 \%$ Triton X-100 for $1 \mathrm{~h}$. For antibody labeling, samples were incubated overnight in preblock solution containing affinitypurified antibodies directed against the intracellular domain of mouse Vlgr1 (a kind gift from Dr. Dominic Cosgrove, Boys Town National Research Hospital) or nonimmune rabbit Ig, washed three times with TBS, and incubated for an additional $2 \mathrm{~h}$ in preblock containing Alexa 488-conjugated goat anti-rabbit IgG (1:500 dilution; Invitrogen, Paisley, UK) and Texas Red-conjugated phalloidin (1:200 dilution; Invitrogen). To visualize hair bundles, cochlear whole mounts were stained with rhodamine-conjugated phalloidin $(0.1 \mu \mathrm{g} / \mathrm{ml}$; Sigma, Poole, UK) in preblock for 2-12 h.

Immunogold labeling. Cochlear cultures were prepared from postnatal day 2 (P2) CD1 mice as described previously (Russell and Richardson, 1987), except that the medium contained 93\% DMEM/F-12, 7\% fetal bovine serum and $10 \mu \mathrm{g} / \mathrm{ml}$ ampicillin. After $1 \mathrm{~d}$ in vitro, the cultures were washed three times with HBHBSS, fixed, preblocked, and reacted with anti-mouse Vlgr1 antibodies as described above. After extensive washing with TBS $/ 0.05 \%$ Tween 20 , cultures were incubated with $5 \mathrm{~nm}$ gold-conjugated goat anti-rabbit IgG (1:10 dilution; BBInternational, Cardiff, UK) for $24 \mathrm{~h}$ in TBS/0.05\% Tween/10\% horse serum, washed, refixed with $2.5 \%$ glutaraldehyde in $0.1 \mathrm{~m}$ sodium cacodylate buffer, $\mathrm{pH}$ 7.2 , containing $0.5 \%$ ruthenium red, washed in cacodylate buffer, and postfixed in $1 \%$ osmium tetroxide. Samples were dehydrated in ethanol, embedded in Epon, and sectioned at a thickness of 100 or $200 \mathrm{~nm}$. Sections were counterstained with uranyl acetate and lead citrate and viewed in a Hitachi (Wokingham, UK) 7100 electron microscope operating at 75 or $100 \mathrm{kV}$, and images were captured with a Gatan (Abingdon, UK) digital camera.

Scanning electron microscopy. For scanning electron microscopy (SEM), animals were perfused as described below (see below, Cochlear histology), and, after postfixation, the cochleae were perfused with $0.1 \mathrm{M}$ 
phosphate buffer and then osmicated. After decalcification in $120 \mathrm{~mm}$ EDTA for 1-1.5 h and transfer to phosphate buffer, each cochlea was divided into three longitudinal sections. The lateral wall was trimmed away, and the tectorial membrane was removed to expose the reticular lamina and apical surface of the sensory epithelium. Each turn was dehydrated

and critical point dried, mounted on a stub, sputter coated, and viewed on a Jeol (Welwyn Garden City, UK) T220A scanning microscope.

FM1-43 uptake and hair cell transduction currents. FM1-43 [N-(3triethylammonium)propyl)-4-(4-(dibutylamino)styryl) pyridinium dibromide] dye loading with cochlear cultures was done as described previously (Gale et al., 2001), using a concentration of $3 \mu \mathrm{M}$ and a $10 \mathrm{~s}$ dip time. Live cultures were viewed with a $63 \times$ water immersion lens and photographed with a Spot RT CCD camera at time points varying from 5 to $7 \mathrm{~min}$ after dye application. For quantification, gray level values in images of the cytoplasmic regions of the dye-loaded hair cells were measured in Photoshop 7 (Adobe Systems, San Jose, CA), and background levels were subtracted. For acute preparations of the cochlea and vestibule at P7, a $5 \mu \mathrm{M}$ concentration of a fixable analog of FM1-43 (FM143FX; Invitrogen, Carlsbad, CA) was applied for $10 \mathrm{~s}$ and washed out during three full bath replacements. Five minutes later, the cells were fixed in $4 \%$ paraformaldehyde overnight at $4^{\circ} \mathrm{C}$. After three $10 \mathrm{~min}$ washes in PBS, cells were incubated in 1:100 AlexaFluor-633 phalloidin (Invitrogen) for $45 \mathrm{~min}$. After three more $10 \mathrm{~min}$ PBS rinses, the epithelia were embedded in FluoroGuard (Bio-Rad, Hercules, CA), coverslipped, and imaged using an LSM 510 confocal microscope (Zeiss, Oberkochen, Germany) equipped with a $63 \times$ oil immersion objective. Identical laser intensity, pin hole, gain, and contrast settings were used for image acquisition. MetaMorph 6.2 (Universal Imaging Corporation, West Chester, PA) was used to estimate the mean FM1-43FX fluorescence of individual hair cells.

Dissection, recording, and stimulation of mouse utricular hair cells in intact epithelia were performed as described previously (Holt et al., 1997, 2002). Cochleae were excised from the bony capsule in MEM supplemented with 10 mm HEPES, pH 7.4. After exposing the organ of Corti, the apical turn $(\sim 10 \%$ from the apex $)$ was excised and the tectorial membrane was carefully peeled away. The sensory epithelia from either the utricle or organ of Corti was mounted on a glass coverslip in an experimental chamber and viewed on an Axioskop FS upright microscope (Zeiss) equipped with a $63 \times$ water-immersion objective and differential interference contrast optics.

Electrophysiological recordings were performed in solutions containing the following (in mM): $137 \mathrm{NaCl}, 5.8 \mathrm{KCl}, 10 \mathrm{HEPES}, 0.7 \mathrm{NaH}_{2} \mathrm{PO}_{4}$, 1.3 $\mathrm{CaCl}_{2}, 0.9 \mathrm{MgCl}_{2}$, and $5.6 \mathrm{D}$-glucose, vitamins, and amino acids as in MEM (Invitrogen), pH 7.4 (311 mOsm/kg). Recording electrodes (3-5 $\mathrm{M} \Omega$ ) were pulled from R-G glass (Garner Glass, Claremont, CA) and were filled with the following (in mM): $135 \mathrm{KCl}, 5 \mathrm{EGTA}-\mathrm{KOH}, 5 \mathrm{HEPES}$, $2.5 \mathrm{Na}_{2} \mathrm{ATP}, 2.5 \mathrm{MgCl}_{2}$, and $0.1 \mathrm{CaCl}_{2}$, pH $7.4(284 \mathrm{mOsm} / \mathrm{kg})$. The whole-cell, tight-seal technique was used to record hair cell currents at -64 mV using an Axopatch 200B or Multiclamp 700A amplifier (Molecular Devices, Palo Alto, CA). Currents were filtered at $1 \mathrm{kHz}$ with a low-pass Bessel filter, digitized at $\geq 5 \mathrm{kHz}$ with a 12-bit acquisition board (Digidata 1322A), and recorded using pClamp 8.2 software (Molecular Devices).

Utricular hair bundles were stimulated as described previously (Holt et al., 1997, 2002). The stimulus pipette was driven by a piezoelectric device that had a $10-90 \%$ rise time of $0.6 \mathrm{~ms}$. Cochlear outer hair cells (OHCs) were stimulated by a fluid jet or stiff probe. For fluid-jet stimulation, glass micropipettes were pulled to a tip diameter of $\sim 5 \mu \mathrm{m}$, filled with standard extracellular solution, and positioned $\sim 10 \mu \mathrm{m}$ from the hair bundle. The fluid jet was controlled by an HSPC-1 fast pressureclamp system (ALA Scientific Instruments, Westbury, NY). For stiffprobe stimulation, the end of a pulled micropipette was heated to create a rounded end that was placed inside the "V" shape of the hair bundle. Hair bundle deflections were monitored by video microscopy using a CCD camera (Hamamatsu, Shizouka, Japan).

Cochlear histology. Animals were perfused systemically with $0.1 \mathrm{M}$ phosphate buffer and fixed with $2.5 \%$ glutaraldehyde, $1 \%$ paraformaldehyde, $0.25 \%$ tannic acid, and $3 \mathrm{~mm} \mathrm{CaCl}_{2}$ in $0.1 \mathrm{~m}$ phosphate buffer. The
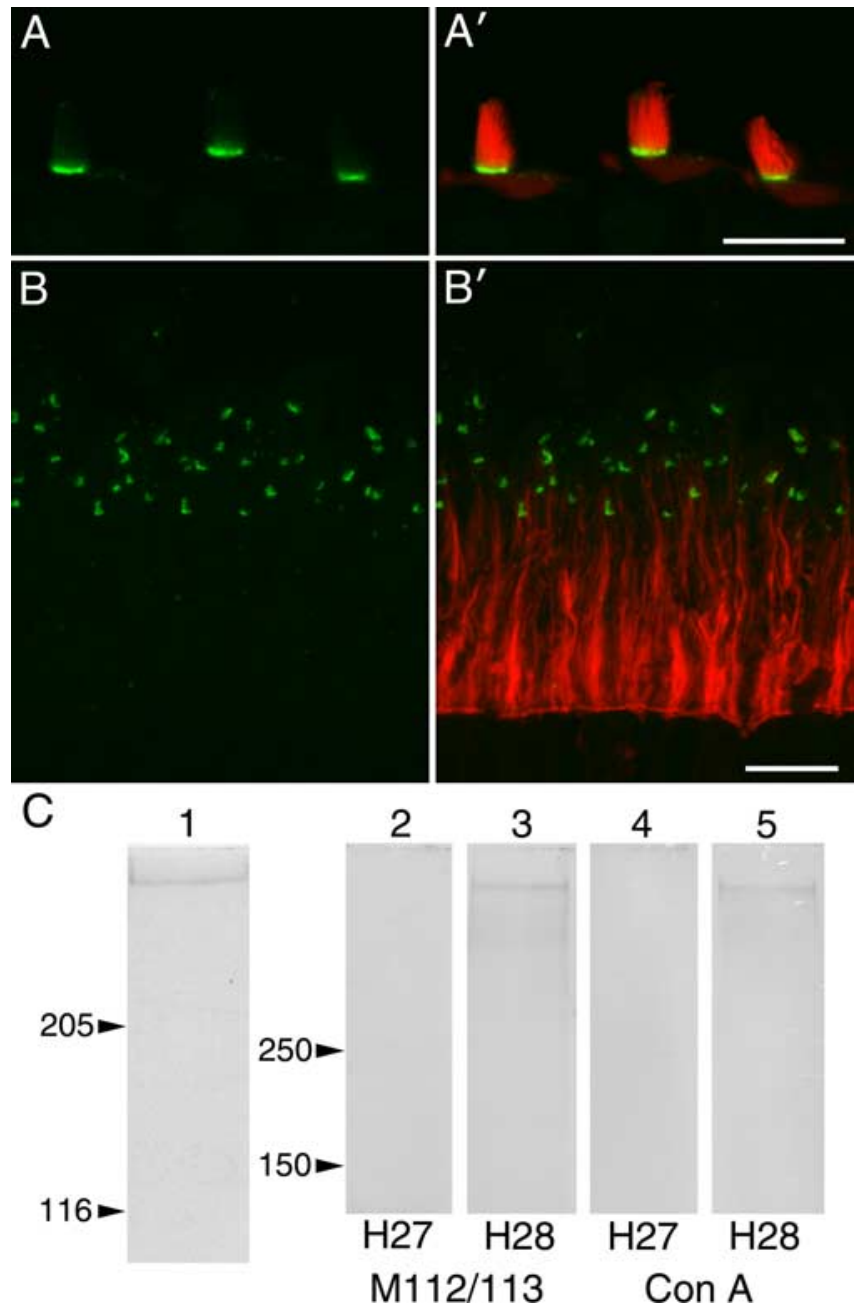

4

5

Figure 1. Ankle link antigen distribution in ear and eye and its identification as avian Vlgr1. $A, B$, Cryosections of the avian basilar papilla $\left(\boldsymbol{A}, \boldsymbol{A}^{\prime}\right)$ and retina $\left(\boldsymbol{B}, \boldsymbol{B}^{\prime}\right)$ double labeled with anti-ALA mAb (green) and Texas Red phalloidin (red). $\boldsymbol{A}, \boldsymbol{B}$, Single-channel images of ALA distribution; $\boldsymbol{A}^{\prime}, \boldsymbol{B}^{\prime}$, merges of ALA and F-actin distribution. The ALA is restricted to the basal region of the hair bundle $(\boldsymbol{A})$ and to the ciliary calyx of the photoreceptors $(\boldsymbol{B})$. Scale bars, 10 $\mu \mathrm{m}$. C, Lane 1, Coomassie-stained gel of the ALA immunoprecipitated from a Triton X-100 soluble extract of the avian retina with anti-ALA mAb H28. Lanes 2-5, Blots of immunoprecipitates obtained from retinal extracts with anti-ALA mAb H28 (lanes 3, 5) or irrelevant mAb H27 (lanes 2, 4) probed with mouse anti-chick Vlgr1 sera (M112/M113) and biotinylated ConA.

stapes was removed, and fixative was perfused through the oval window. After an overnight postfixation at $4^{\circ} \mathrm{C}$, the cochleae were perfused with $1 \%$ buffered $\mathrm{OsO}_{4}$ for $30 \mathrm{~min}$, dehydrated in graded ethanols followed by propylene oxide, and embedded in epoxy resins. After polymerization, the undecalcified temporal bone was removed, the cochlear duct was sectioned into pieces $\sim 1 \mathrm{~mm}$ in length, and those pieces were reembedded in epoxy resin. Each plastic-embedded piece of the organ of Corti was subsequently thinned and glued to a microscope slide, allowing the entire sensory epithelium from apex to base to be viewed as a surface preparation. Cell counts (cytocochleograms) were made along the entire length of the cochlea and expressed as a function of cochlear distance, which was measured at the level of the heads of pillar cells. Histological analyses were performed using high-resolution, differential interference contrast microscopy, and images were digitally captured. After quantification, cochlear segments were removed from the slide, trimmed and blocked to $\sim 1 \mathrm{~mm}^{2}$, and radially oriented to yield organ of Corti cross-sections.

Auditory brainstem responses. Auditory brainstem responses (ABRs) were used to assess the integrity of the cochlea and auditory brainstem (Walsh et al., 1986). Platinum subdermal needle electrodes (Grass Instruments, Quincy, MA) were positioned at the vertex (active, non- 
inverting), infra-auricular region (reference, inverting), and in the neck region (ground). Differentially recorded scalp potentials were amplified 100,000 times, bandpass filtered between 0.03 and $10 \mathrm{kHz}$ (model P511K; Grass Instruments), and digitized (Tucker-Davis Technologies, Gainesville, FL) using a $20 \mathrm{kHz}$ sampling rate over a $15 \mathrm{~ms}$ epoch. A total of 200 trials were averaged for each waveform, and two waveforms were obtained for each stimulus condition. Digitized response waveforms were displayed in real time during recording sessions, and trials with extraneously high voltages attributable to muscle or electrocardiographic artifact were excluded from the average and the trial repeated. On completion of a run, response waveforms were stored digitally for off-line analyses. Threshold was defined as the lowest stimulus level eliciting an unambiguous, replicable response. Custom software was used for data acquisition and subsequent analyses.

Stimuli consisted of symmetrically shaped tone bursts that were $3 \mathrm{~ms}$ long ( $1 \mathrm{~ms}$ raised cosine on/off ramps and $1 \mathrm{~ms}$ plateau) and clicks that were $64 \mu$ s in duration. Both clicks and tone bursts were generated digitally using a clock rate of $125 \mathrm{kHz}$ and delivered free field via a high-impedance piezoelectric tweeter (Radio Shack) positioned $10 \mathrm{~cm}$ from the vertex. Stimulus levels were calibrated using a 0.5 inch Brüel and Kjær (Norcross, GA) microphone (model 4134) positioned at the approximate location of the subject's head during recording sessions and are reported in decibels sound pressure level (dB SPL; referenced to $20 \mu \mathrm{Pa}$ ). Stimuli of alternating polarity were delivered at an interval of $75 \mathrm{~ms}$. ABR thresholds were determined for clicks and for tone bursts in half-octave steps ranging from 32 to $2.0 \mathrm{kHz}$. Stimulus levels ranged from suprathreshold values ( $>50 \mathrm{~dB}$ above threshold when possible) to threshold in $10 \mathrm{~dB}$ steps. Near threshold, levels were changed in $5 \mathrm{~dB}$ steps.

Distortion product otoacoustic emission procedures. Distortion product otoacoustic emission (DPOAEs) were used to assess outer hair cell function (Walsh and McGee, 2001). Stimuli consisted of two phase-locked tones of different frequency $\left(f_{1}<f_{2}\right)$ generated by 16-bit digital-toanalog converters and delivered to separate earphones, so that the two tones combine acoustically. Primary frequencies were adjusted to an $f_{2} / f_{1}$ ratio of $\sim 1.25$, and the level of $f_{2}$ was set $10 \mathrm{~dB}$ lower than $f_{1}$. The earphone outputs, along with a low-distortion, probe microphone (ER10B; Etymotic Research, Elk Grove Village, IL) were sealed within the external ear canal, forming a closed acoustic system. The microphone signal was amplified $40 \mathrm{~dB}$ and synchronously sampled with a 16-bit analog-to-digital converter. Artifact rejection was used to eliminate signals containing extraneous noise. The digitized signals were separated into two independent buffers and averaged over repeated trials until one of three criteria was met: the period of averaging equaled $30 \mathrm{~s}$, the noise floor equaled or fell below $-25 \mathrm{~dB}$ SPL, or the signal-to-noise ratio equaled or exceeded $30 \mathrm{~dB}$. The sum of the two partial averages was used to obtain the DPOAE (as well as stimulus levels recorded in the ear canal), and the difference was used to estimate the noise floor. Stimulus levels were calibrated in vivo at the beginning of every measurement series (approximately every 5-10 min) using the probe microphone. Fast Fourier transform analyses were used on-line and off-line to compute amplitudes and phases of component DPOAEs and corresponding noise floors.

Electroretinograms. Full-field electroretinograms (ERGs) were obtained in a Ganzfeld dome from Vlgr1/del7TM homozygous mutant mice and littermate controls ( 10 mice of each genotype in each of two age groups). Mice were dark adapted overnight before testing. After pupil dilation (scopolamine hydrobromide), mice were anesthetized with a saline solution containing ketamine $(40 \mathrm{mg} / \mathrm{ml})$ and xylazine $(2 \mathrm{mg} / \mathrm{ml})$. Anesthetized mice were kept on a heating pad at $37^{\circ} \mathrm{C}$ during recordings. A gold-wire coil placed on one cornea was referenced to a needle electrode in the scalp. A needle electrode in the tail served as ground. Signals were amplified and filtered [AM502 differential amplifier (Tektronix, Wilsonville, OR); 10,000 $\times ; 3 \mathrm{~dB}$ down at 2 and 10,000 Hz), digitized (sampling rate, $1.25-5 \mathrm{kHz}$ ), and averaged on a personal computer. Two different flash stimulators were used. A Grass Instruments photostimulator provided short-wavelength $20 \mu \mathrm{s}$ flashes [-0.3 log scotopic troland-seconds (scot td-s); Wratten 47A; max, $470 \mathrm{~nm}$, half-bandwidth, $55 \mathrm{~nm}$ ] to elicit rod-only ERGs and achromatic flashes of $1.4 \mathrm{log}$ photopic troland-s to elicit mixed rod and cone responses. Cone ERG responses were isolated by presenting the achromatic flashes on a rod-saturating $\left(40 \mathrm{~cd} / \mathrm{m}^{2}\right)$ background. A Novatron (Dallas, TX) flash unit produced short-wavelength $1.3 \mathrm{~ms}$ flashes (Wratten W47B; max, $449 \mathrm{~nm}$; halfbandwidth, $47 \mathrm{~nm}$ ) from 1 to $3.4 \log$ scot td-s in $0.3 \log$ unit steps. Data were analyzed by ANOVA using genotype and age group as factors.

Retinal histology. Wild-type and mutant mice were killed using $\mathrm{CO}_{2}$, and the eye cups were removed and fixed in $4 \%$ paraformaldehyde in 0.1 м PBS, pH 7.4, for $1 \mathrm{~h}$ at $4^{\circ} \mathrm{C}$. The cornea and lens were removed, and fixation continued overnight at $4^{\circ} \mathrm{C}$. Eye cups were dehydrated through a graded ethanol series, embedded in Epon resin medium, and allowed to polymerize overnight at $64^{\circ} \mathrm{C}$. Sections were examined from two quadrants around the optic nerve, and sections of $0.5 \mu \mathrm{m}$ thickness were stained with $1 \%$ toluidine blue for light microscopy.

\section{Results}

\section{The ALA is an epitope of Vlgr1}

Immunofluorescence studies of cryosections of the avian basilar papilla (Fig. $1 A$ ) and retina (Fig. $1 B$ ) demonstrated that the ALA is restricted to the basal region of the hair bundle (Fig. $1 A$ ) and to the ciliary calyx of the photoreceptors (Fig. $1 B$ ). 


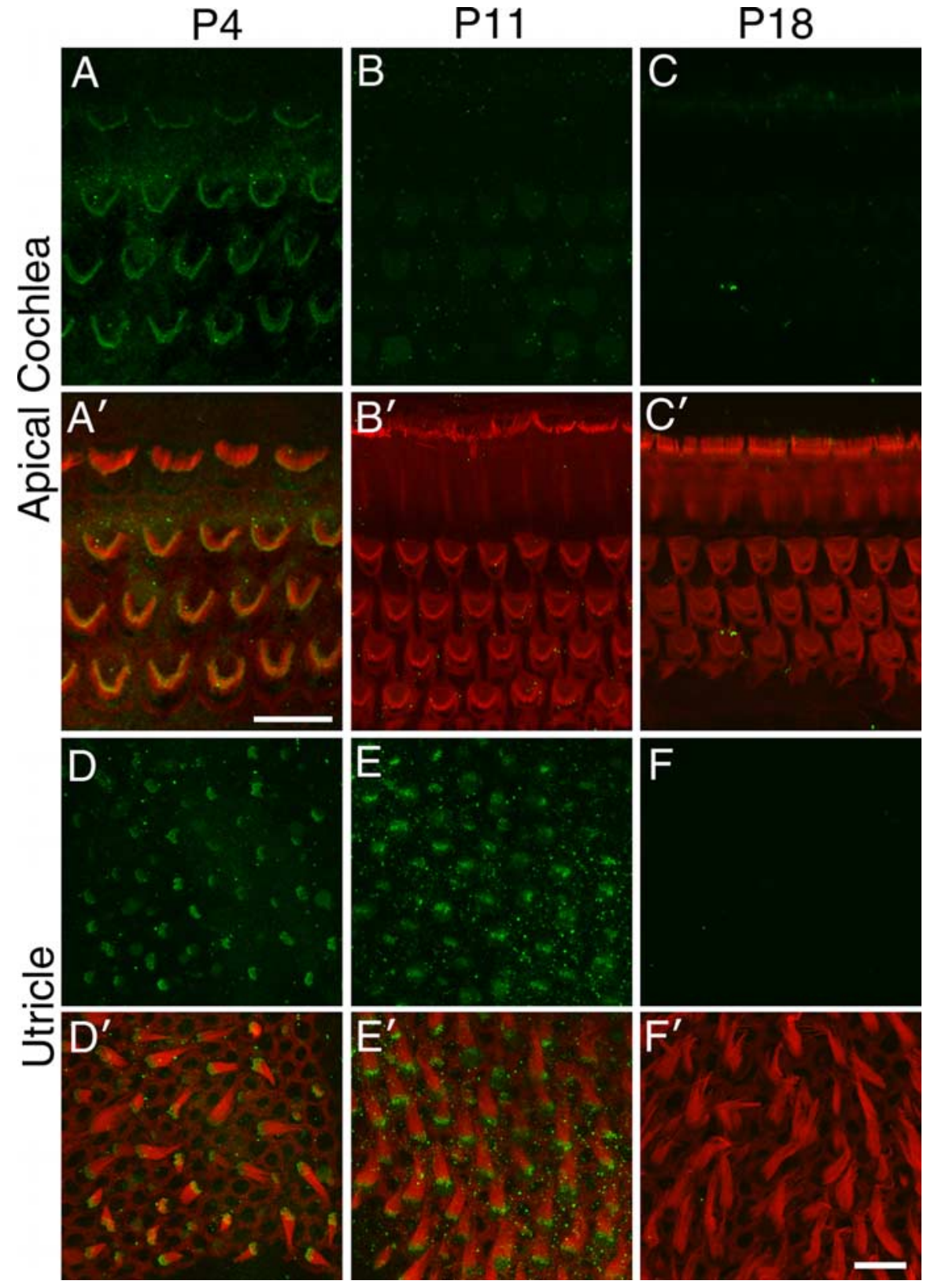

Figure 3. Vlgr1 distribution during postnatal development of the hair bundle. Confocal images of hair bundles from the cochlea $(\boldsymbol{A}-\boldsymbol{C})$ and utricle $(\boldsymbol{D}-\boldsymbol{F})$ at P4 $(\boldsymbol{A}, \boldsymbol{D}), \mathrm{P} 11(\boldsymbol{B}, \boldsymbol{E})$, and P18 $(\boldsymbol{C}, \boldsymbol{F})$ double labeled with anti-Vlgr1 antibodies (green) and Texas Red phalloidin (red). VIgr1 disappears from hair bundles in the cochlea by P11 and from the utricle by P18. Scale bars: $A, 10$ $\mu \mathrm{m} ; \boldsymbol{F}^{\prime}, 10 \mu \mathrm{m}$ (applies to $\boldsymbol{B}-\boldsymbol{F}$ ).

The ALA was immunoprecipitated from Triton X-100 extracts of chick retina, isolated by one-dimensional gel electrophoresis (Fig. 1C, lane 1), and digested with trypsin. The resultant tryptic peptides were analyzed by LC-MS/MS. A single peptide sequence (LGSTPTSGASIDPEK) identified the ALA as an avian ortholog of VLGR1 (Mascot score of $65 ; p<0.05$ ). This peptide is located in the extracellular domain of VLGR1 (position 16751689). To confirm this result, the ALA was immunoprecipitated from retinal extracts with the anti-ALA mAb and Western blotted with mouse sera raised to recombinant fragments of chick Vlgr1 or as previously described (Goodyear and Richardson, 2003), with ConA. A single band of high molecular mass was detected in extracts precipitated with the anti-ALA mAb blotted with the mouse anti-chick Vlgr1 sera or with ConA but not in extracts precipitated with an irrelevant control $\mathrm{mAb}$ of the same isotype (Fig. $1 C$, lanes $2-5)$.

Vlgr1 is transiently expressed during hair bundle development

An antibody to the recombinant intracellular domain of mouse Vlgr1 was used to study the distribution of Vlgr1 in the hair bundles of cochlear cultures prepared from the early postnatal mouse inner ear (Fig. 2). Confocal microscopy revealed intense staining around the base of the hair bundle in both the basal and apical coils of 1-d-old cultures prepared from P2 mice (Fig. 2A,B). Such staining was not observed in the hair bundles of cultures prepared from homozygous Vlgr1/del7TM mice (Fig. 2C). Ankle links are long, singlestranded filaments that form a dense web or mesh around the base of the hair bundle just above the region in which the stereocilia begin to taper down (Fig. 2 D). Immunogold labeling confirmed that the antibody reacted predominantly in this region of the hair bundle (Fig. 2E).

Although ankle links are found in mature hair bundles of frogs, fishes, and birds, they are only a transient feature of developing mouse cochlear hair bundles, present predominantly from P2 through P9, and are absent by P12 (Goodyear et al., 2005). Whole-mount preparations of the developing inner ear were used to examine the distribution of Vlgr1 as a function of age. Immunofluorescence microscopy indicated that Vlgr1 was present in cochlear hair bundles from wild-type mice at $\mathrm{P} 4$ but not at either P11 or P18 (Fig. 3A-C). In the utricle of the vestibular system, the expression of Vlgr1 persisted for longer, being present at both $\mathrm{P} 4$ and $\mathrm{P} 11$, but was no longer detectable by P18 (Fig. 3D-F).

\section{Ankle links are absent in Vlgr1/del7TM} mutant mice

Transmission electron microscopy was used to examine the distribution of ankle links in cochlear cultures prepared from heterozygous and homozygous Vlgr1/del7TM mice (Fig. 4). For both inner (Fig. $4 A$ ) and outer (Fig. $4 B$ ) hair cells of heterozygous mice, ankle links were readily visible spanning the gaps between the stereocilia around the base of the developing hair bundle. Ankle links were not detected in any of the hair bundles examined from homozygous Vlgr1/del7TM mice, for either inner (Fig. 4C) or outer (Fig. $4 D$ ) hair cells.

\section{Hair bundles become disorganized in Vlgr1/del7TM mutant} mice by postnatal day 2

Cochlear hair bundle morphology was examined using confocal microscopy of phalloidin-stained whole-mounts and SEM (Fig. 5). At P0, hair bundles in the apical coils of heterozygous and homozygous Vlgr1/del7TM mutant mice were indistinguishable 

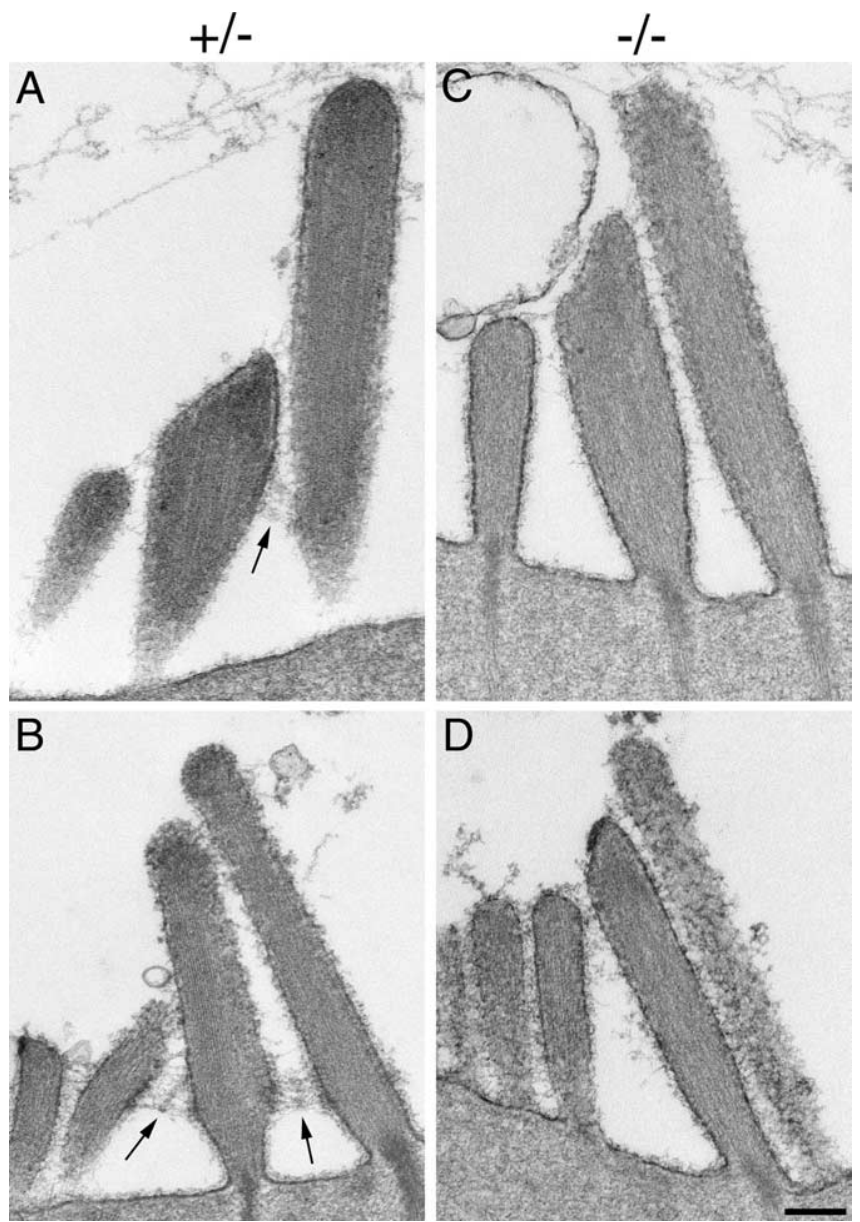

Figure 4. Link distribution in Vlgr1/del7TM mouse hair cells. Transmission electron micrographs of the hair bundles of inner $(A, C)$ and outer $(B, D)$ hair cells from tannic acid-stained cochlear cultures prepared from heterozygous $(\boldsymbol{A}, \boldsymbol{B})$ and homozygous $(\boldsymbol{C}, \boldsymbol{D})$ Vlgr1/del7TM mice. Arrows indicate the ankle links that are present in the hair bundles of the heterozygous Vlgr1/del7TM mice. Scale bar, $200 \mathrm{~nm}$.

(Fig. 5A,B). By P2, subtle differences in hair bundle morphology became apparent, with many of the outer hair bundles in the homozygous mutant exhibiting a less sharply defined $\mathrm{V}$-shape relative to those in heterozygous outer hair cells (Fig. $5 C, D$ ). By $\mathrm{P} 4$, a clear change in hair bundle morphology became visible, with hair bundles in the homozygous mutant having a more rounded shape, lacking bilateral symmetry, and showing a degree of disorientation (Fig. 5 E, F ). SEM of the cochlea at P28 indicates there is little additional progression in the hair bundle phenotype with age (Fig. 5G,H).

\section{Hair cells transduce in early postnatal Vlgr1/del7TM mutant mice}

We measured the uptake of the styryl dye FM1-43, which permeates nonselective cation channels in sensory cells (Gale et al., 2001; Meyers et al., 2003), to determine the functional status of the hair cell transduction channels. In cochlear cultures at the equivalent age of $\mathrm{P} 3$, dye loading levels in the apical-coil hair cells (Fig. $6 A, C$ ) of mutant cultures were reduced to $40.6 \%$ of those observed in heterozygous cultures [ $96 \pm 15.1$ (mean \pm SD of gray level values) for $n=30$ heterozygous cells; $39 \pm 7.9$ for $n=30$ homozygous mutant cells]. In basal-coil cultures (Fig. 6B,D), there was more evidence of hair bundle disruption in mutant cultures, and dye loading levels in cells were reduced to $32.1 \%$ of
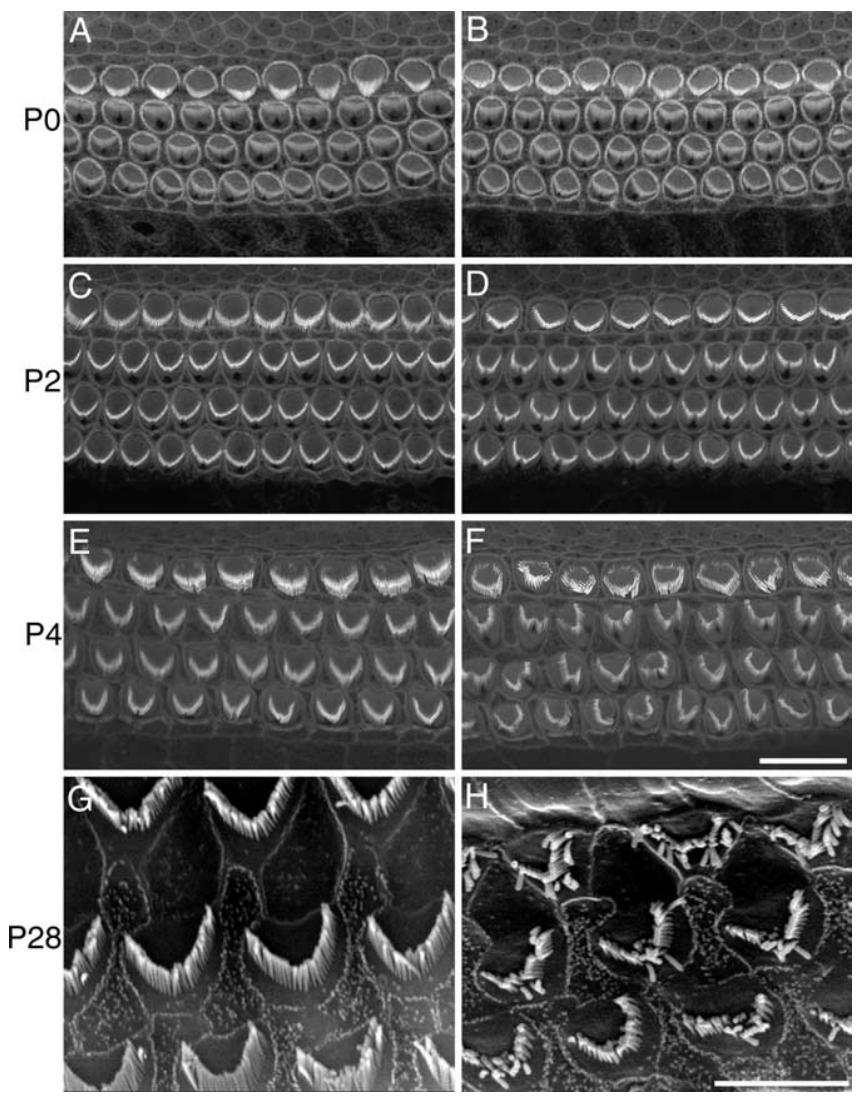

Figure 5. Hair bundle morphology in Vlgr1/del7TM mice. $\boldsymbol{A}-\boldsymbol{F}$, Confocal images of phalloidin-stained whole mounts from the apical coils of heterozygous $(\boldsymbol{A}, \boldsymbol{C}, \boldsymbol{E})$ and homozygous $(\boldsymbol{B}, \boldsymbol{D}, \boldsymbol{F})$ Vlgr1/del7TM mice. A phenotype is first readily detectable in apical coils at $\mathrm{P} 2$ ( $\boldsymbol{C}$, D) and is more pronounced by $P 4(\boldsymbol{E}, \boldsymbol{F})$. Scale bar, $10 \mu \mathrm{m} . \mathbf{G}, \boldsymbol{H}$, Scanning electron micrographs of the surface of the organ of Corti from the middle turn of the cochlea of a wild-type mouse $(\boldsymbol{G})$ and a 1-month-old VLGR1/del7TM homozygous mutant mouse $(\boldsymbol{H})$. Scale bar, $5 \mu \mathrm{m}$.

those in cultures prepared from heterozygous littermates (140 \pm 14.8 for $n=30$ heterozygous cells; $45 \pm 15.1$ for $n=30$ homozygous cells). At P7, uptake of FM1-43FX in both inner and outer hair cells of Vlgr1 mutant mice of acute preparations (Fig. $6 \mathrm{~F}$ ) was also significantly reduced relative to wild-type controls (Fig. $6 E)$, consistent with a greatly diminished number of transduction channels open at rest. The fluorescence was $23 \pm 4$ arbitrary units (a.u. mean $\pm \mathrm{SD} ; n=30$ ) in cochlear hair cells from mutant mice and $99 \pm 16$ a.u. $(n=30)$ in wild-type cells. In contrast, FM1-43FX uptake in Vlgr1 mutant hair cells located in the utricular macula epithelium ( $123 \pm 35$ a.u.; $n=30)$ was very similar to that observed in wild-type controls at P7 (118 \pm 35 a.u.; $n=30)$ (Fig. 6G,H).

To quantitatively assess transduction currents, outer hair cells were studied after the deflection of hair bundles using either a stiff probe or a fluid jet, and recordings were made using the wholecell tight-seal technique. Transduction current with maximum amplitudes ranging from 300 to $600 \mathrm{pA}$ were measured in nine of nine hair cells sampled from wild-type animals (Fig. 6I). Although normal voltage-dependent currents were present (data not shown), transduction currents were absent in 10 of 11 Vlgr 1 mutant outer hair cells ( $\mathrm{P} 6-\mathrm{P} 8)$ when stimuli covering a wide range of bundle positions, which included off-axis stimulation, were considered (Fig. $6 \mathrm{~K}$ ). The one transducing cell had maximal currents of only $20 \mathrm{pA}$.

Transduction currents in four Vlgrl mutant utricular hair cells were indistinguishable from those from wild-type animals 

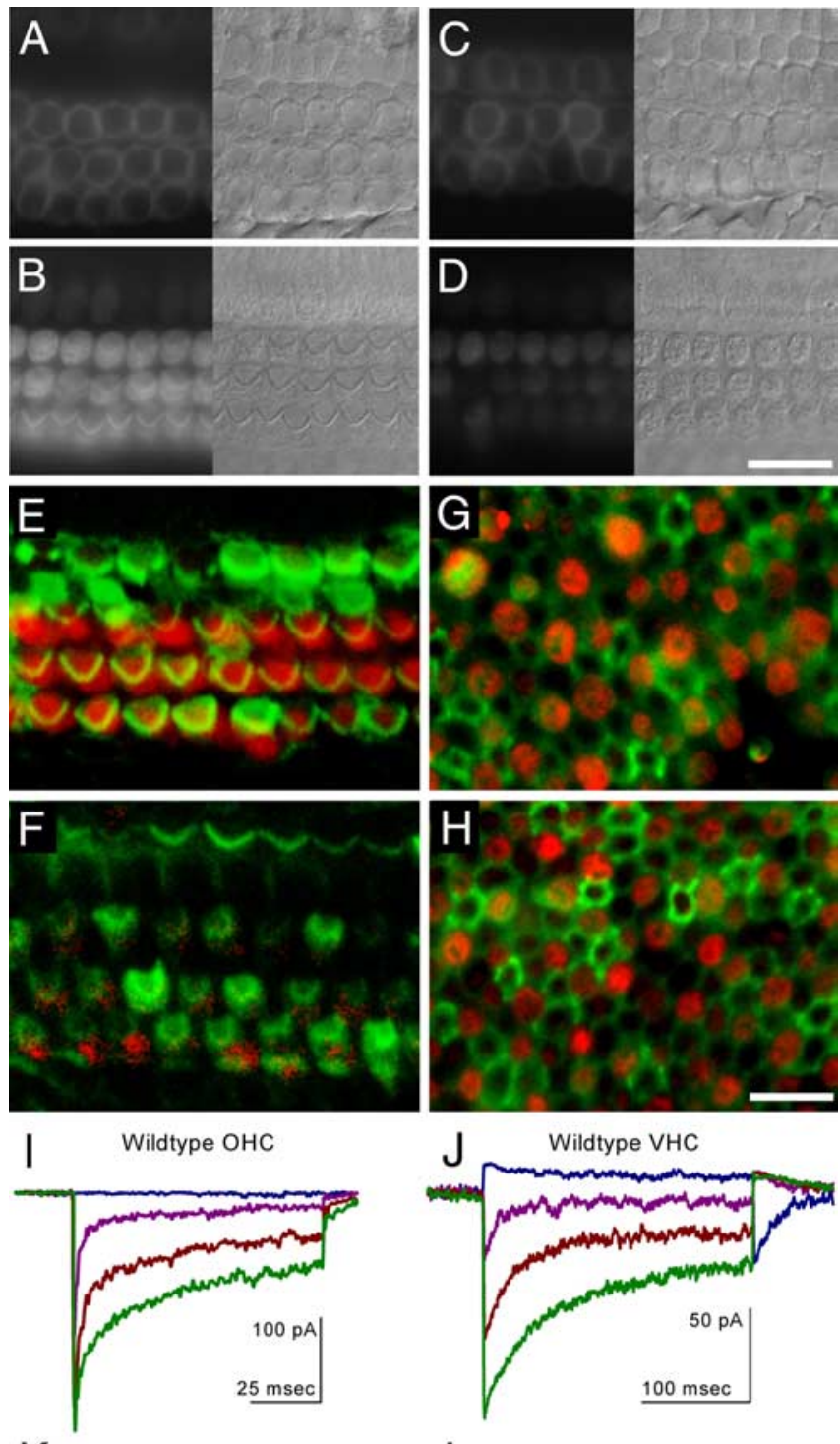

$\mathrm{K}$

VLGR1 Mutant OHC
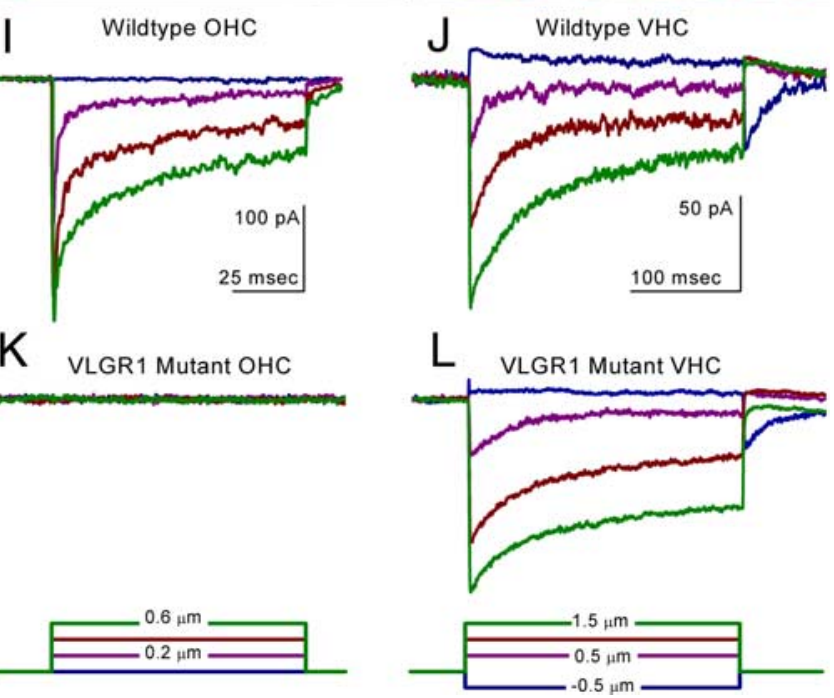

Figure 6. FM1-43 dye loading and transduction currents in Vlgr1/del7TM mutant mice. FM1-43 dye loading $(A-D)$ of hair cells in cochlear cultures prepared from the apical $(A, C)$ and basal $(\boldsymbol{B}, \boldsymbol{D})$ coils of heterozygous $(\boldsymbol{A}, \boldsymbol{B})$ and homozygous $(\boldsymbol{C}, \boldsymbol{D})$ Vlgr1/del7TM mice. Nomarski interference contrast images of the cells are shown adjacent to $\boldsymbol{A}-\boldsymbol{D}$. Images in $\boldsymbol{A}$ and $\boldsymbol{C}$ are focused at the level of the nucleus and were captured $6 \mathrm{~min}$ after the dye dip, and images in $\boldsymbol{B}$ and $\boldsymbol{D}$ are focused at the level of the hair bundle and were captured $5 \mathrm{~min}$ after the dye dip. Scale bar, $10 \mu \mathrm{m}$. Confocal images of FM1-43FX uptake (red) and phalloidin staining (green) in control $(\boldsymbol{E}, \boldsymbol{G})$ and VIgr1/del7TM mutant $(\boldsymbol{F}, \boldsymbol{H})$ mouse hair cells at P7 from sensory cell epithelia excised from the apical turn of the cochlea $(\boldsymbol{E}, \boldsymbol{F})$ and from the utricle $(\boldsymbol{G}, \boldsymbol{H})$. Scale bar, $10 \mu \mathrm{m}$. Transduction current recordings in control $(\boldsymbol{I}, \boldsymbol{J})$ and Vlgr1/del7TM mutant $(\boldsymbol{K}, \boldsymbol{L})$ mouse hair cells at P7 from apical turn $0 \mathrm{HCs}$ of the cochlea $(\boldsymbol{I}, \boldsymbol{K})$ and from vestibular hair cells (VHC) acquired from the utricle $(\boldsymbol{J}, \boldsymbol{L})$. Calibration in $\boldsymbol{I}$ and $\boldsymbol{J}$ apply to $\boldsymbol{K}$ and $\boldsymbol{L}$, respectively.
(Fig. 6J,L) and from findings reported previously (Holt et al., 1997, 2002; Stauffer et al., 2005).

Basal-turn hair cells are lost in Vlgr1/del7TM mice by 2 months of age

By 2 months of age, the organ of Corti in the basal, highfrequency turn of the Vlgr1/del7TM mutant cochlea showed considerable signs of degeneration relative to age-matched controls. Significant OHC loss was observed in the basal half of the cochlea, and the condition progressively worsened in more extreme basal regions to encompass the loss of inner hair cells (IHCs) and the inner and outer pillar cells (Fig. $7 B$ ). This loss of pillar cells resulted in the complete collapse of the end organ in the basal turn of the cochlea. Although unambiguously pathological, the middle (Fig. 7A) and apical turns were less extensively affected at this age, with cytopathology generally limited to disarrayed stereociliary bundles (data not shown).

The magnitude of cell loss in the basal turn of the cochlear spiral was quantified in 2-month-old mice (Fig. 7C,D). Aside from the loss of $\mathrm{OHCs}$ populating the outermost row in the most basal $10 \%$ of the cochlea, a full complement of IHCs, OHCs, and pillar cells was observed in wild-type animals (Fig. 7C). In mutant animals, both hair cells and pillar cells were missing from much of the basal half of the cochlea (Fig. 7D). A loss of OHCs populating the innermost row was especially conspicuous in mutant mice, a finding that runs contrary to $\mathrm{OHC}$ loss patterns observed in older wild-type animals or among animals exposed to traumatizing noise or ototoxic agents.

\section{VLGR/del7TM mutant mice are profoundly deaf by 3 weeks of age}

Because transduction currents were observed in a subset of $\mathrm{OHCs}$ and FM1-43 dye loading was observed in hair cells from mutant mice, albeit at a reduced level, the functional status of the system was evaluated using ABRs. Although ABR thresholds were considerably elevated in Vlgr1/del7TM mutant mice, the ABR waveforms appeared normal, exhibiting five and occasionally six distinct positive-going voltage deflections within the first $10 \mathrm{~ms}$ of stimulation with high-level signals (Fig. $8 A, B$ ), indicating that the gross organization of the auditory CNS is normal in mutant animals.

Wild-type animals acquired adult-like sensitivity to airborne sounds by the end of the third postnatal week, except for lower stimulus frequencies ( 2 and $2.8 \mathrm{kHz}$ ) (Fig. 8C). At 6 months of age, wild-type animals were less sensitive than 3 -week-old mice to stimuli above $\sim 16 \mathrm{kHz}$. This finding likely reflects age-related high-frequency hearing loss, because the C57BL/6J strain carries an age-related hearing loss $(A h l)$ allele at the $C d h 23$ locus (Noben-Trauth et al., 2003). The overall shape of the thresholdfrequency curve in 3-week-old Vlgr1/del7TM homozygous mutant mice was similar to that of normal mice (Fig. 8C). However, thresholds were elevated $\sim 20 \mathrm{~dB}$ for responses to low-frequency stimulation $(2-2.8 \mathrm{kHz})$ and $\sim 60 \mathrm{~dB}$ for responses to the higherfrequency stimuli. By 6 months of age, average threshold values for mutant animals increased (sensitivity decreased) by $\sim 10 \mathrm{~dB}$ for responses to higher-frequency stimuli $(>10 \mathrm{kHz})$, with values of 95-100 dB SPL regardless of stimulus frequency. Likewise, fewer 6-month-old mutant mice were responsive to the highest levels of stimulation $(>105 \mathrm{~dB}$ SPL) at high frequencies $(>10$ $\mathrm{kHz}$ ) compared with 3-week-old mutant animals (Fig. 8D). Under similar stimulus conditions at corresponding ages, all wildtype animals were responsive. Although mean threshold estimates representing 6-month-old heterozygotes were consistently 
elevated relative to age-matched wild-type animals, these differences were not statistically significant.

Stereociliary abnormalities and the degree of hearing loss observed in mutant mice suggested that $\mathrm{OHC}$ function might be compromised in affected animals. Abnormalities affecting OHCs necessarily affect the production of DPOAEs, making the response a useful indicator of their function. Based on response spectra computed from the acoustic signal recorded from the external ear canal (fast Fourier transformations of the temporal response waveform), normal DPOAEs were observed in wild-type animals but were completely absent in mutant mice (Fig. $8 E$ ). In normal animals, DPOAEs were dependent on both stimulus frequency and intensity but were not detectable in mutants, as shown in plots of DPOAE level versus $f_{2}$ stimulus frequency in Figure $8 F$, i.e., acoustic energy recorded within the ear canal of mutant animals was limited to the primary stimulus frequencies and did not contain energy at the cubic distortion frequency regardless of level.

\section{Age-related loss of visual function in Vlgr1/del7TM mutant mice}

Gross retinal abnormalities were not detected by funduscopic examination of Vlgr1/del7TM mutants (data not shown), but electroretinographic analyses suggest that the overall mutant phenotype includes age-related loss of visual function. No significant differences in ERG responses were observed between wild-type and mutant animals at 6-months of age or between wild-types at 6 and 15 months of age (Table 1, Fig. 9). In contrast, the amplitudes of component waves of electroretinograms were smaller $(26-37 \%$ decrease) in 15-month-old mutant mice for all stimulus conditions, but these differences (evaluated as genotype $\times$ age interaction by ANOVA) were significant only for light-adapted cone-only responses. Gross retinal histology appeared normal in Vlgr1/ del7TM mutants, consistent with funduscopic observations (data not shown).

\section{Discussion}

\section{Vlgr1 is a component of the ankle}

link complex

We present three lines of evidence that Vlgr1 is a component of the ankle link complex of the sensory hair bundle. First, mass spectrometry and Western blot analysis identify the ALA, an extracellular antigen specifically associated with ankle links, as an epitope of avian Vlgr1. Second, the spatiotemporal distribution of Vlgr1 closely matches that reported for ankle links using transmission electron microscopy in the developing mouse cochlea (Good-
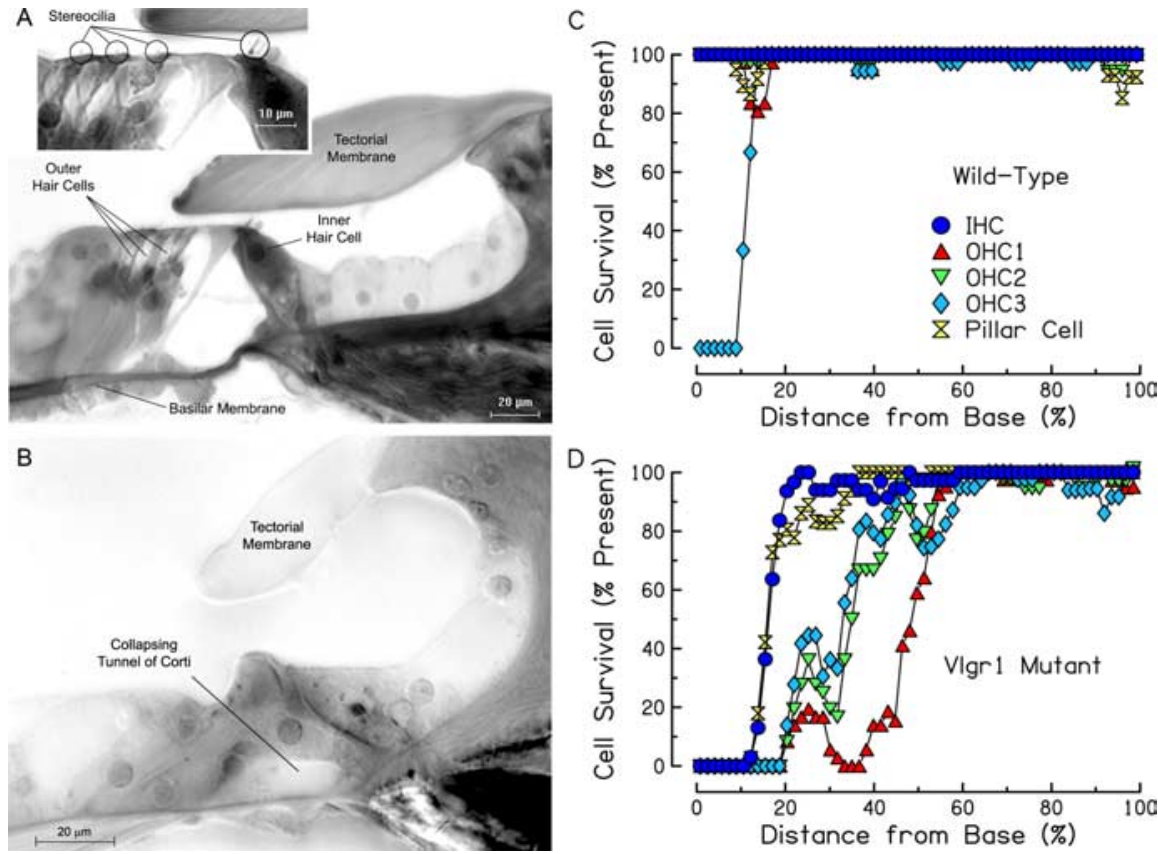

Figure 7. Hair cell loss in Vlgr1/del7TM mice. Cross-sections of the organ of Corti from the middle $(\boldsymbol{A})$ and basal (B) cochlear coils harvested from a 2-month-old Vlgr1/del7TM mutant mouse, along with cytocochleograms from 2-month-old wild-type (C) and Vlgr1/del7TM mutant (D) mice.
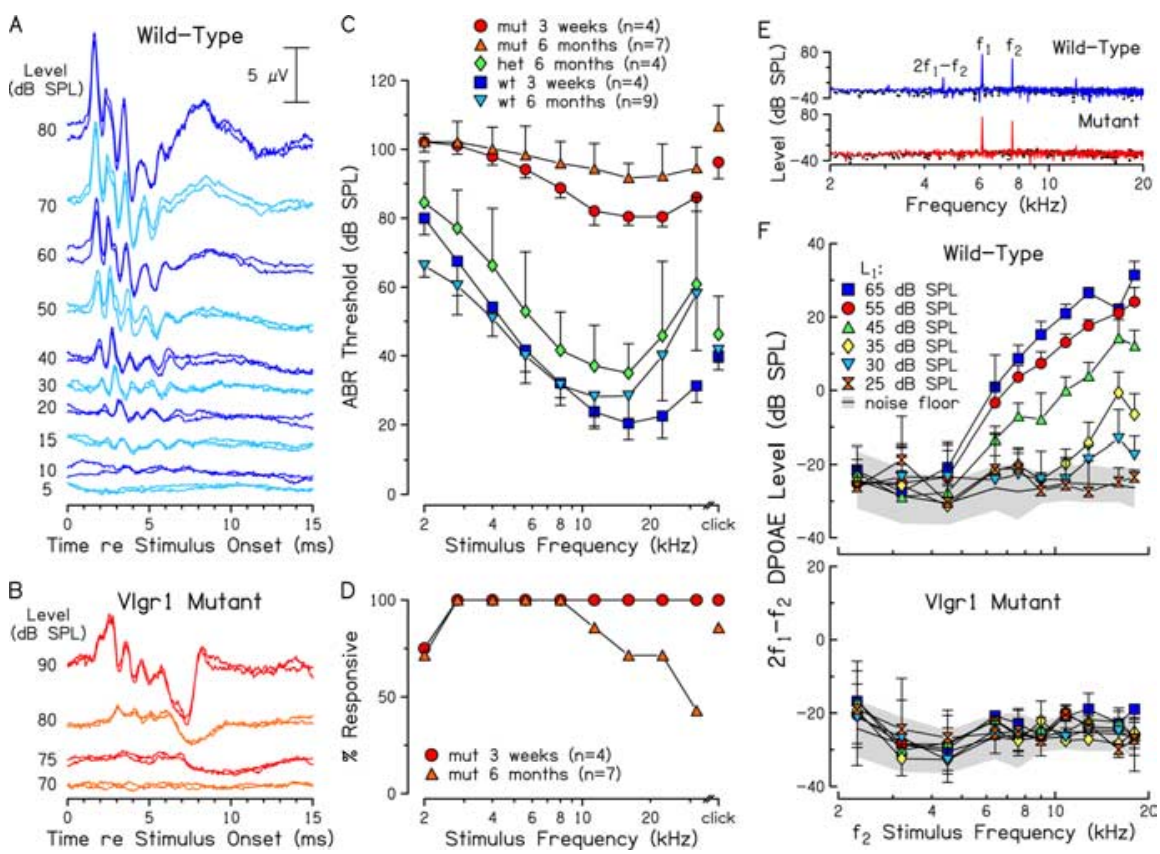

Figure 8. Auditory function in VIgr1/del7TM mice. $\boldsymbol{A}, \boldsymbol{B}$, Representative examples of $A B R$ waveforms for a wild-type $(\boldsymbol{A})$ and Vlgr1/del7TM homozygous mutant (B) mouse. $\boldsymbol{C}$, ABR audiograms for control [wild-type (wt)], heterozygous (het), and homozygous mutant (mut) mice. $\boldsymbol{D}$, Percentage of VIgr1/del7TM homozygous mutant mice at each of the indicated ages that responded to clicks and tone bursts delivered at the highest stimulus output levels (at least $105 \mathrm{~dB}$ SPL). E, DPOAE response spectra representing a wild-type (top) and mutant (bottom) mouse for a single stimulus condition. $\boldsymbol{F}$, DPOAE $\left(2 f_{1}-f_{2}\right)$ levels as a function of primary frequency from 2-month-old wild-type (top) and homozygous Vlgr1 mutant (bottom) mice. Primary frequencies were maintained at an $f_{2} / f_{1}$ ratio of $\sim 1.2$, and $L_{1}$ was $10 \mathrm{~dB}$ higher than $L_{2}$. Error bars represent $\pm 1 \mathrm{SD}$.

year et al., 2005) and utricle (R. J. Goodyear and G. P. Richardson, unpublished observations). Finally, ankle links are not observed in Vlgr1/del7TM mutant mice that lack hair-bundle-associated Vlgr1.

The ankle link complex is composed of filaments that form a dense web or mesh around the base of the hair bundle. Digital 
Table 1. ERG amplitudes ( $\mu \mathrm{V})$ in wild-type and mutant mice (means $\pm \mathrm{SE}$ )

\begin{tabular}{|c|c|c|c|c|}
\hline & \multicolumn{2}{|c|}{ Wild type } & \multicolumn{2}{|c|}{ Vlgr1/del7TM } \\
\hline & Mean & SE & Mean & SE \\
\hline \multicolumn{5}{|l|}{6 month animals } \\
\hline $\operatorname{Rod}(-0.6 \log s c o t t d-s)$ & 255 & 24 & 251 & 15 \\
\hline Mixed rod-cone (1.8 log scot td-s) & 300 & 19 & 304 & 27 \\
\hline Light-adapted cone (1.4 log photopic td-s) & 104 & 4 & 129 & 8 \\
\hline Rod a-wave $\left(R \mathrm{~m}_{\mathrm{P} 3}\right)$ & -223 & 12 & -255 & 18 \\
\hline \multicolumn{5}{|l|}{ 12-15 month animals } \\
\hline $\operatorname{Rod}(-0.6 \log s \operatorname{sct} t d-s)$ & 217 & 30 & 159 & 18 \\
\hline Mixed rod-cone (1.8 log scot td-s) & 263 & 34 & 171 & 13 \\
\hline Light-adapted cone (1.4 log ph td-s)* & 102 & 19 & 75 & 12 \\
\hline Rod a-wave $\left(R \mathrm{~m}_{\mathrm{P3}}\right)$ & -204 & 25 & -178 & 14 \\
\hline
\end{tabular}

${ }^{*} p<0.05$, significant interaction of mutation and age.

diffraction data from ankle links of chick vestibular hair cells indicate that these filaments have a diameter of $\sim 4 \mathrm{~nm}$ and are composed of globular structures with a spacing of 3-5 nm (Tsuprun et al., 2004). The complex contains central and juxtamembrane regions of increased density. In the auditory papilla of the alligator lizard, the central density is composed of one or two rows of particles that appear to be sites in which the filaments meet or cross over (Csukas et al., 1987).

The structure of Vlgr1 is consistent with it being a principal constituent of the ankle link filament. Vlgr1 is a member of the secretin family (family 2 or B) of G-protein-coupled receptors. It is distinguished by a very large ectodomain consisting mainly of calcium-binding Calx- $\beta$ repeats that resemble the regulatory domains of sodium-calcium exchangers (Nikkila et al., 2000). The tertiary structure of these Calx- $\beta$ repeats is probably calcium dependent, perhaps explaining why the ALA is sensitive to calcium chelation (Goodyear and Richardson, 1999). The threedimensional structure of a Calx- $\beta$ repeat has yet to be solved, but
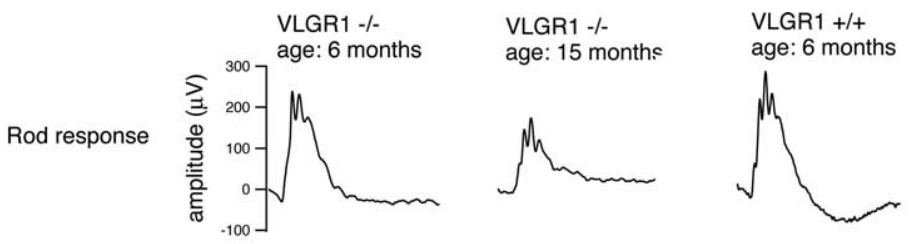

Mixed rod \&
cone response
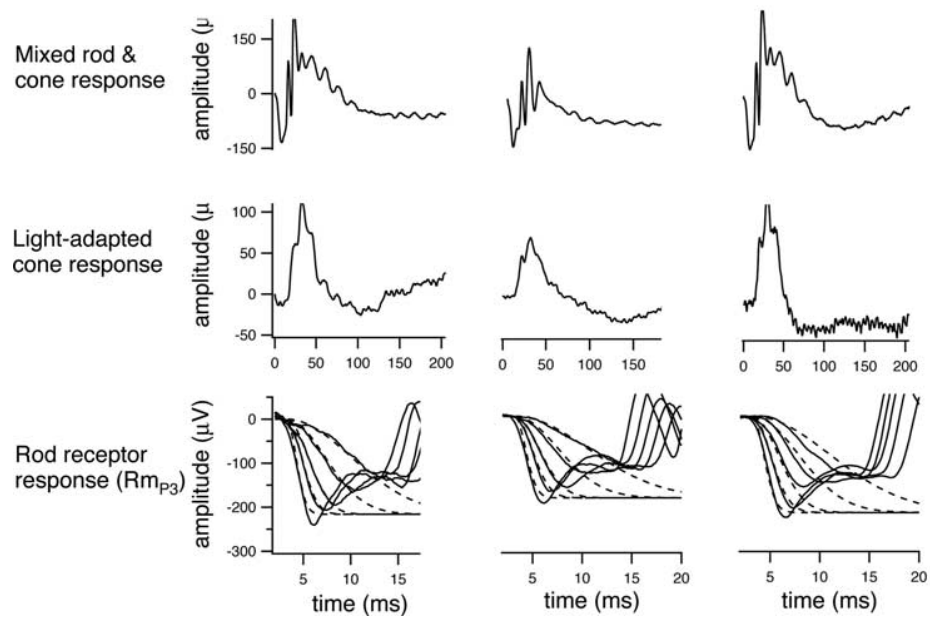

Figure 9. Representative computer-averaged ERG recordings (median responses, see Table 1) from homozygous Vlgr1/ del7TM and wild-type mice at 6 and 15 months of age. The first row shows rod responses to short-wavelength stimuli $\left(\lambda_{\max }=\right.$ $470 \mathrm{~nm} ;-0.3 \log$ scot $t d-s)$. The second row shows mixed rod and cone responses to achromatic stimuli ( $1.4 \log \mathrm{td}-\mathrm{s})$. The third row shows responses to achromatic flashes $(1.4 \mathrm{log} \mathrm{td}-\mathrm{s})$ in the presence of a rod-saturating background $\left(40 \mathrm{~cd} / \mathrm{m}^{2}\right)$. The fourth row shows rod a-waves to short-wavelength stimuli $\left(\lambda_{\max }=449 \mathrm{~nm} ; 1-3.4 \log\right.$ scot $\left.t d-s\right)$ with the rod phototransduction model (Hood and Birch, 1993) fit to the leading edges (dashed curves).
VLGR $1+/+$ age: 15 months
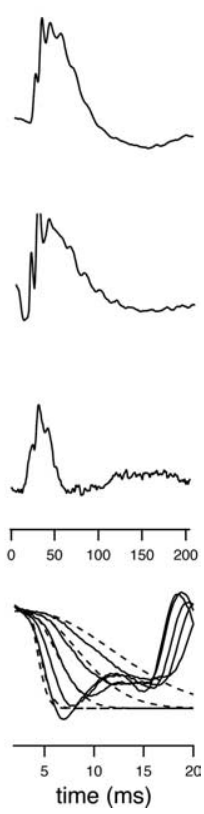

each contains $\sim 120$ amino acids and would have a diameter of $\sim 4 \mathrm{~nm}$ if assumed to be approximately globular. The Vlgr1 ectodomain has 35 Calx- $\beta$ repeats and an estimated length of $\sim 180 \mathrm{~nm}$ (McMillan et al., 2002) so it could readily span the gap region.

The molecular interactions by which VLGR1 ectodomains form ankle links remain to be defined. Although individual filaents of the ankle link complex appear to be single stranded The particles observed within the centra repeats. Usherin isoform $b$, the full-length product of the Usher $2 \mathrm{~A}$ locus, has been proposed to be a component of the ankle link not been able to detect the presence of usherin in the ankle link region of early postnatal mouse hair cells (Goodyear and Rich-

\section{Functional consequences of Vlgr1 mutations}

The Vlgr1/del7TM mice demonstrate that Vlgr1 and the ankle formed ankle links are first observed by transmission electro microscopy (Goodyear et al., 2005) and $\sim 7-8 \mathrm{~d}$ after the hair bundle has first emerged. Vlgr1 is therefore not required for the stages of hair bundle genesis but appears to be critically nvolved in maintaining the form of the bundle once it has reached a certain stage of development. In its absence, cochlear hair bundles lose their tightly defined $\mathrm{V}$-shaped configuration and become poorly aligned. Surprisingly, although developing vestibular hair bundles have ankle links and express Vlgr1, these cells do not appear to be critically dependent on Vlgr1 for their development and longterm survival. Subtle defects in vestibular hair bundle morphology may, however, be hard to detect with the normal variation in hair bundle structure observed in the vestibular organs of wild-type mice, and compensation may account for the lack of an overt behavioral phenotype.

Single-cell recordings reveal that most cochlear OHCs fail to respond to fairly large hair bundle displacements by P7, and FM1-43 dye loading experiments indicate that mechanotransduction is impaired in both inner and outer hair cells. Impaired mechanotransduction most likely reflects the observed disorganization of the hair bundle, although the possibility that Vlgr1 may be required for the correct assembly of the transduction complex of the hair cell cannot be excluded. Vlgr1 is, however, unlikely to be directly involved in mechanotransduction because this process is not affected in the vestibular hair cells of homozygous Vlgr1/del7TM mice. ABRs indicate that Vlgr1 mutant mice are pro- 
foundly deaf by P20, the earliest stage tested, and acoustic sensitivity continues to decrease over the following month. The presence of a residual ABR at P20 and later indicates that the cochlear nerve can be activated by high-level stimuli. The absence of transduction distortion in mutant mice at 2 months of age confirms that OHCs are malfunctioning and therefore unable to amplify basilar membrane motion. Failure of the OHCs to amplify basilar membrane motion, combined with an insensitive mechanotransduction apparatus in IHCs, may mostly account for the elevated ABR thresholds observed in the Vlgr1/del7TM mutant mice.

The physiological phenotype of the Vlgr1/del7TM mutant mice is similar to that observed in humans diagnosed with Usher syndrome 2C (Sadeghi et al., 2004). Specifically, deficits are greatest in the high-frequency range (at 6 months of age, $60 \mathrm{~dB}$ loss at $16 \mathrm{kHz}$ vs $20 \mathrm{~dB}$ loss at $2 \mathrm{kHz}$ ), although mice are generally very insensitive to low-frequency stimuli. The pathology is also progressive in the Vlgr1/del7TM mouse, with early hair bundle defects leading to a complete loss of hair cells in the basal turn of the cochlea by 2 months of age. The normal gait and balance behavior of Vlgr1/del7TM mutant mice and the normal transduction currents measured in their vestibular hair cells, also correspond to the lack of vestibular dysfunction seen in humans with Usher syndrome 2C. Although the retinal pathology observed in the Vlgr1/del7TM mutant mouse does not recapitulate the retinal phenotype observed in Usher syndrome $2 \mathrm{C}$ in humans (i.e., the mice have no evidence of retinitis pigmentosa based on either fundoscopic or histological studies), mouse models of the more severe Usher syndrome type 1 (Libby and Steel, 2001; Libby et al., 2003) have, at most, mild abnormalities of retinal function similar to those observed here. The calycal processes with which the ALA is associated (Goodyear and Richardson, 1999) are well developed in the photoreceptors of frogs (Fetter and Corless, 1987), fishes (Collin et al., 1996), chicks (Goodyear and Richardson, 1999), and primates (Rana and Taraszka, 1991) but are not a prominent feature of the mouse retina (Cohen, 1963). This may be one reason why mice with mutations in Usher genes do not provide good models for the retinal condition. Alternatively, mice may simply not live long enough, because blindness in humans with Usher syndrome only becomes apparent in the second decade of life (Iannaccone et al., 2004; Schwartz et al., 2005).

In conclusion, the results of this study further emphasize the critical role inter-stereocilial links play in the development and maintenance of hair-bundle structure. Cadherin 23, a member of the cell-cell adhesion molecule superfamily, and the two transmembrane receptors Vlgr 1 and Ptprq are components of at least three of the different link types present on the surface of the developing hair bundle. Each protein has a distinct spatiotemporal expression pattern and is likely to regulate a specific aspect of hair bundle development. Future studies should be directed at understanding how the different expression patterns are determined and how the individual proteins control the various phases of hair-bundle morphogenesis.

\section{References}

Adato A, Lefevre G, Delprat B, Michel V, Michalski N, Chardenoux S, Weil D, El-Amraoui A, Petit C (2005) Usherin, the defective protein in Usher syndrome type IIA, is likely to be a component of interstereocilia ankle links in the inner ear sensory cells. Hum Mol Genet 14:3921-3932.

Assad JA, Shepherd GM, Corey DP (1991) Tip-link integrity and mechanical transduction in vertebrate hair cells. Neuron 7:985-994.

Cohen AI (1963) Vertebrate retinal cells and their organization. Biol Rev 38:427-459.

Collin SP, Collin HB, Ali MA (1996) Ultrastructure and organisation of the retina and pigment epithelium in the cutlips minnow, Exoglossum maxillingua (Cyprinidae, Teleostei). Histol Histopathol 11:55-69.

Csukas SR, Rosenquist TH, Mulroy MJ (1987) Connections between stereocilia in auditory hair cells of the alligator lizard. Hear Res 30:147-155.

Fetter RD, Corless JM (1987) Morphological components associated with frog cone outer segment disc margins. Invest Ophthalmol Vis Sci 28:646-657.

Gale JE, Marcotti W, Kennedy HJ, Kros CJ, Richardson GP (2001) FM1-43 dye behaves as a permeant blocker of the hair-cell mechanotransducer channel. J Neurosci 21:7013-7025.

Goodyear R, Richardson G (1992) Distribution of the 275 kD hair cell antigen and cell surface specialisations on auditory and vestibular hair bundles in the chicken inner ear. J Comp Neurol 325:243-256.

Goodyear R, Richardson G (1999) The ankle-link antigen: an epitope sensitive to calcium chelation associated with the hair-cell surface and the calycal processes of photoreceptors. J Neurosci 19:3761-3772.

Goodyear RJ, Richardson GP (2003) A novel antigen sensitive to calcium chelation that is associated with the tip links and kinocilial links of sensory hair bundles. J Neurosci 23:4878-4887.

Goodyear RJ, Legan PK, Wright MB, Marcotti W, Oganesian A, Coats SA, Booth CJ, Kros CJ, Seifert RA, Bowen-Pope DF, Richardson GP (2003) A receptor-like inositol lipid phosphatase is required for the maturation of developing cochlear hair bundles. J Neurosci 23:9208-9219.

Goodyear RJ, Marcotti W, Kros CJ, Richardson GP (2005) Development and properties of stereociliary link types in hair cells of the mouse cochlea. J Comp Neurol 485:75-85.

Holt JR, Corey DP, Eatock RA (1997) Mechanoelectrical transduction and adaptation in hair cells of the mouse utricle, a low-frequency vestibular organ. J Neurosci 17:8739-8748.

Holt JR, Gillespie SK, Provance DW, Shah K, Shokat KM, Corey DP, Mercer JA, Gillespie PG (2002) A chemical-genetic strategy implicates myosin-1c in adaptation by hair cells. Cell 108:371-381.

Hood DC, Birch DG (1993) Light adaptation of human rod receptors: the leading edge of the human a-wave and models of rod receptor activity. Vision Res 33:1605-1618.

Iannaccone A, Kritchevsky SB, Ciccarelli ML, Tedesco SA, Macaluso C, Kimberling WJ, Somes GW (2004) Kinetics of visual field loss in Usher syndrome type II. Invest Ophthalmol Vis Sci 45:784-792.

Libby RT, Steel KP (2001) Electroretinographic anomalies in mice with mutations in Myo7a, the gene involved in human Usher syndrome type 1B. Invest Ophthalmol Vis Sci 42:770-778.

Libby RT, Kitamoto J, Holme RH, Williams DS, Steel KP (2003) Cdh23 mutations in the mouse are associated with retinal dysfunction but not retinal degeneration. Exp Eye Res 77:731-739.

McMillan DR, White PC (2004) Loss of the transmembrane and cytoplasmic domains of the very large G-protein-coupled receptor-1 (VLGR1 or Mass1) causes audiogenic seizures in mice. Mol Cell Neurosci 26:322-329.

McMillan DR, Kayes-Wandover KM, Richardson JA, White PC (2002) Very large $\mathrm{G}$ protein-coupled receptor-1, the largest known cell surface protein, is highly expressed in the developing central nervous system. J Biol Chem 277:785-792.

Meyers JR, MacDonald RB, Duggan A, Lenzi D, Standaert DG, Corwin JT, Corey DP (2003) Lighting up the senses: FM1-43 loading of sensory hair cells through nonselective ion channels. J Neurosci 15:4054-4065.

Michel V, Goodyear RJ, Weil D, Marcotti W, Perfettini I, Wolfrum U, Kros CJ, Richardson GP, Petit C (2005) Cadherin 23 is a component of the transient lateral links in the developing hair bundles of cochlear sensory cells. Dev Biol 280:281-294.

Nikkila H, McMillan DR, Nunez BS, Pascoe L, Curnow KM, White PC (2000) Sequence similarities between a novel putative $G$ protein-coupled receptor and $\mathrm{Na}^{+} / \mathrm{Ca}^{2+}$ exchangers define a cation binding domain. Mol Endocrinol 14:1351-1364.

Noben-Trauth K, Zheng QY, Johnson KR (2003) Association of cadherin 23 with polygenic inheritance and genetic modification of sensorineural hearing loss. Nat Genet 35:21-23.

Pickles JO, Comis SD, Osborne MP (1984) Cross-links between stereocilia in the guinea pig organ of Corti, and their possible relation to sensory transduction. Hear Res 15:103-112.

Rana MW, Taraszka SR (1991) Monkey photoreceptor calycal processes and interphotoreceptor matrix as observed by scanning electron microscopy. Am J Anat 192:472-477. 
Russell IJ, Richardson GP (1987) The morphology and physiology of hair cells in organotypic cultures of the mouse cochlea. Hear Res 31:9-24.

Sadeghi M, Cohn ES, Kelly WJ, Kimberling WJ, Tranebjoerg L, Moller C (2004) Audiological findings in Usher syndrome types IIa and II (nonIIa). Int J Audiol 43:136-143.

Schwartz SB, Aleman TS, Cideciyan AV, Windsor EA, Sumaroka A, Roman AJ, Rane T, Smilko EE, Bennett J, Stone EM, Kimberling WJ, Liu XZ, Jacobson SG (2005) Disease expression in Usher syndrome caused by VLGR1 gene mutation (USH2C) and comparison with USH2A phenotype. Invest Ophthalmol Vis Sci 46:734-743.

Siemens J, Lillo C, Dumont RA, Reynolds A, Williams DS, Gillespie PG, Muller U (2004) Cadherin 23 is a component of the tip link in hair-cell stereocilia. Nature 428:950-955.

Sollner C, Rauch GJ, Siemens J, Geisler R, Schuster SC, Muller U, Nicolson T (2004) Mutations in cadherin 23 affect tip links in zebrafish sensory hair cells. Nature 428:955-959.
Stauffer EA, Scarborough JD, Hirono M, Miller ED, Shah K, Mercer JA, Holt JR, Gillespie PG (2005) Fast adaptation in vestibular hair cells requires Myosin-1c activity. Neuron 47:541-553.

Tsuprun V, Goodyear RJ, Richardson GP (2004) The structure of tip links and kinocilial links in avian sensory hair bundles. Biophys J 87:4106-4112.

Walsh EJ, McGee J (2001) Hypothyroidism in the Tshr mutant mouse. In: Handbook of mouse auditory research: from behavior to molecular biology (Willott J, ed), pp 537-555. Boca Raton, FL: CRC.

Walsh EJ, McGee J, Javel E (1986) Development of auditory-evoked potentials in the cat. I. Onset of response and development of sensitivity. J Acoust Soc Am 79:712-724.

Weston MD, Luijendijks MWJ, Humphreys KD, Mollers C, Kimberling WJ (2004) Mutations in the VLGR1 gene implicate G-protein signaling in the pathogenesis of Usher syndrome type II. Am J Hum Genet 74:357366. 